\title{
Towards a Carbon-Neutral Environment, the Role of Biomass Energy Consumption and Trade Openness in Sub-Saharan Africa: A Spatial Econometric Analysis
}

\section{Emmanuel Sogbou Kenne ( $\nabla$ kelpats@yahoo.fr)}

East China Jiaotong University

Cheng Zhang

East China Jiaotong University

Weihua Gan

East China Jiaotong University

Olivier Abban

Jiangsu University

Emmanuel Owusu

Jiangsu University

Shangui Hu

Ningbo University of Finance and Economics

\section{Research Article}

Keywords: Trade openness, Biomass energy, Carbon-neutral, Environment, Africa

Posted Date: March 7th, 2022

DOI: https://doi.org/10.21203/rs.3.rs-1387344/v1

License: (c) (i) This work is licensed under a Creative Commons Attribution 4.0 International License.

Read Full License 


\title{
Towards a carbon-neutral environment, the role of biomass energy consumption and trade openness in Sub-Saharan Africa: A spatial econometric analysis.
}

\author{
Emmanuel Sogbou Kenne ${ }^{1}$, Cheng Zhang ${ }^{1}$, Weihua Gan ${ }^{1}$, Olivier Joseph Abban², Emmanuel \\ Owusu $^{3}$, Shangui $\mathrm{Hu}^{4}$
}

${ }^{1}$ School of Transportation, East China Jiaotong University, 808 Shuanggang new development Zone, Nanchang City, Jiangxi Province, 330013, China.

${ }^{2}$ School of Mathematical Sciences, Institute of Applied Systems and Analysis (IASA), Jiangsu University, Zhenjiang 212013, P.R China

${ }^{3}$ School of Finance and Economics, Jiangsu University, Zhenjiang 212013, P.R China.

${ }^{4}$ College of Business Administration, Ningbo University of Finance \& Economics, Ningbo, Zhejiang, China.

Corresponding author:

Emmanuel Sogbou Kenne

E-mail: kelpats@yahoo.fr 


\begin{abstract}
Energy consumption is known as the catalyst for economic growth, however, the association of $\mathrm{CO}_{2}$ emissions with energy consumption has prompted policymakers to pursue types of energy that ensure sustainable development. This paper analyses the spillover effect of $\mathrm{CO}_{2}$ emissions and the marginal effect of Biomass energy consumption on $\mathrm{CO}_{2}$ emissions in Sub-Saharan Africa by applying the extended Stochastic Impacts by Regression on Population, Affluence, and Technology (STIRPAT) model together with the spatial econometric models. The likelihood ratio test and Wald test indicated that the Spatial Durbin Model was the most suitable model to explain the elasticities of the exogenous variables. Furthermore, the Hausman test performed revealed that the fixed-effects model was more adept than the random-effects model. The findings suggested that increasing biomass energy consumption in a local country turns to reduce the country's own $\mathrm{CO}_{2}$ emissions and also reduces the $\mathrm{CO}_{2}$ emissions of its adjacent countries by $0.089 \%$ and $0.022 \%$ respectively. Whereas an increment in trade openness in a country pollutes its environment and that of its neighboring states by $0.163 \%$ and $0.035 \%$ respectively. Comparing the indirect effect of the employed exogenous variables, foreign direct investment exerted a heavier weight impact than the others. Overall the study spotlighted some policies suggestions for the Sub-Saharan Africa states' energy market in the cause of controlling the emissions of $\mathrm{CO}_{2}$.
\end{abstract}

Keywords: Trade openness, Biomass energy, Carbon-neutral, Environment, Africa 


\section{Introduction}

Carbon dioxide $\left(\mathrm{CO}_{2}\right)$ levels in the atmosphere have risen from 19,809 to 33, 431 million tons in the last decades, reaching it's greatest level in recorded history (Dudley, 2018), posing health risks to human survival and other forms of life. $\mathrm{CO}_{2}$ emissions account for more than $76 \%$ of greenhouse gas (GHG) emissions and are responsible for climate change and global warming (Abban et al., 2020; Khan, 2021). Studies on energy consumption that results in $\mathrm{CO}_{2}$ emissions, notably from fossil fuels as an energy source, are hotly contented (Bakke, 2021). As a result, preventing pollution and climate change has become a priority, leading to the demand for clean energy to reduce rising environmental contamination (Alola et al., 2021; Carley \& Konisky, 2020). The most effective methods for tackling escalating environmental concerns are the creation and utilization of clean energy sources such as bioenergy and other renewable energies. By altering the pattern of energy consumption and production, biomass energy usage and development may be the cornerstone of a sustainable energy system that may efficaciously conduce to economic growth while also strengthening environmental auspices (Sulaiman \& Abdul-Rahim, 2020).

Biomass energy, as a component of renewable energy, occupies a prominent position in global discussions about energy strategies and policy for long-term development (Ajmi \& Inglesi-Lotz, 2020). Biomass energy meets approximately $35 \%$ of the energy needs of several developing countries, bringing global consumption to $13 \%$ (Ulucak, 2020). There are three kinds of biomass energy; (a) animal waste which is obtained from animal husbandry; (b) non-woody biomass energy is obtained from residues mainly residential waste such as food detritus and sewage; bagasse, husks, sawdust, and nutshells; (c) non-woody biomass which is created in crop residues such as plants stem, leaves and straw (Abdulyekeen et al., 2021). Biomass energy could be utilized for heat and energy generation, transportation fuel, and chemical manufacturing, both indirectly and directly. Direct biomass energy usage, involves combustion for cooking, heating, and industrial processes, while indirect usage involves the conversion of biomass into secondary energy consumption (All sources of energy that result from the transformation of primary sources) (Zhang et al., 2020). To sustain future economic development, the world requires an enormous quantity of energy Millward-Hopkins et al. (2020), and bioenergy has the potential to address environmental issues such as air 
pollution, climate change, acidic rain, and global warming by reducing $\mathrm{CO}_{2}$ emissions and other pollutant gas emissions (Gao \& Zhang, 2021; Zafar et al., 2021).

By meeting Africa's expanding energy demand, biomass is predicted to become one of the key domestic energy sources (Sulaiman \& Abdul-Rahim, 2020). Bioenergy is the principal source of energy for approximately 2.7 billion people globally, accounting for approximately $40 \%$ of the total energy supply, particularly SSA. This share is much higher than most developing countries and it is expected to expand in the coming decades (Nyika et al., 2020). Since access to energy, particularly renewable energy, is critical for SSA, which is experiencing economic development and progress in human development, sustainable energy (Biomass) is the measure to replace the heavy dependency on fossil fuels (Gyamfi et al., 2021; Wang et al., 2020). Increased $\mathrm{CO}_{2}$ emissions from increasing energy usage (fossil fuels) to support rapid economic expansion has been a key policy issue in SSA (Karnauskas et al., 2020). The process of producing national output appears to be linked to extremely high $\mathrm{CO}_{2}$ emissions in SSA. For example, the average per capita income in SSA climbed modestly from $\$ 655$ in 1990 to $\$ 1,597$ in 2018 . However, the average $\mathrm{CO}_{2}$ emission in SSA increased by $32.29 \%$ from $13,665.48$ metric tons to 24636.55 metric tons over the same period (Author's computation). In light of the foregoing, the relationship between biomass energy consumption and $\mathrm{CO}_{2}$ in SSA must be investigated in order to guide policies for long-term growth and development.

Due to the influence of composition, scale, technique, trade openness can have either positive or negative effects on environmental pollution (Mutascu, 2018). Mahmood et al. (2019) revealed that the impact of trade openness on environmental pollution is through economic growth, as the scale effect of energy consumption grows. It reveals that economic growth has a negative environmental impact at the early stages of development, however, due to the effect of technique and/or composition, it may have a favorable environmental influence later on (Ansari et al., 2020). Since more focus is placed on economic growth rather than pollution ascendance at the beginning of a development process, the scale effect shows that pollution is increasing due to larger economic activity and energy consumption. If the scale effect of trade openness is determined to be dominant over the composition/technique effect, a net negative environmental effect is expected; in the opposite case, net positive environmental benefits are expected 
(Mahmood et al., 2019). Furthermore, trade openness might have asymmetrical effects on pollutant emissions, because rising trade openness does not always have the same sign and magnitude as decreasing trade openness. Rahman et al. (2020) posit that rising trade openness leads to increased energy consumption and pollution as a country's affluence rises. According to this reasoning, increasing and decreasing trade openness will have an unseen effect on environmental pollution.

The majority of the studies cited above focused on the causal association between $\mathrm{CO}_{2}$ emissions, trade openness, and biomass energy in the presence of other variables. This research adds to the body of knowledge in two ways: first, unlike prior Sub-Saharan African studies, this study unveiled the spillover effect of $\mathrm{CO}_{2}$ emissions in the region. It is general knowledge that sovereign nations with land border constraints can nonetheless interact spatially freely. Validating the spatial dependence of $\mathrm{CO}_{2}$ emissions informs critical policy decisions in international organizations focused on $\mathrm{CO}_{2}$ emissions, hence this research is vital. Secondly, this study uncovered both direct and indirect effects of the exogenous variables, which is essential for integrated policy options on sustainable development in SSA. By understanding the direct and indirect effects of the exogenous variables on $\mathrm{CO}_{2}$ emissions, this study can assist governments in mitigating $\mathrm{CO}_{2}$ emissions across the region.

\section{Methodology}

\subsection{Model Specification}

$\mathrm{CO}_{2}$ emissions have been studied extensively from a variety of perspectives as a worldwide issue. The STRIPAT model is one of the often used tools for analyzing the impact of anthropogenic causes on air pollution indicators such as $\mathrm{CO}_{2}$ emissions. According to literature, Ehrlich and Holdren (1971) were the first to explain the IPAT identity, also known as I = PF, which was the first to demonstrate the relationship between environment and population. Where $\mathrm{I}=$ stands for environmental influence, $P$ for population size, and F for a function that calculates the effect of per capita. In 1972, the IPAT identity became wellknown courtesy of Ehrlich and Holdren (1972) as;

$$
I=P A T
$$


Where $A$ represents affluence and T for technology. Several IPAT identity reforms have been carried out, by introducing additional elements, for example (Schulze, 2002; Waggoner \& Ausubel, 2002). Because it is only an identity, the IPAT identity and all its reformulations were regarded as overly simplistic because it does not account for non- prepositional modification or hypothesis testing in human indicators. To address these problems, Dietz and Rosa (1994) proposed recasting the IPAT model as STIRPAT, this allows for random errors in parameter estimation and provide a testable model for estimating the effects of anthropogenic causes on $\mathrm{CO}_{2}$ and other emissions. The model was reformulated as follow;

$$
I=\alpha P^{\beta} A^{\gamma} T^{\delta} \varepsilon
$$

In applying the natural logarithm to the above equation, we obtained

$$
\operatorname{Ln}(I)=\alpha+\beta \operatorname{Ln}(P)+\gamma \operatorname{Ln}(A)+\delta \operatorname{Ln}(T)
$$

Where $\beta, \gamma$ and $\delta$ are considered as elasticities for population, affluence, and technology, $\alpha$ for the constant term and $\varepsilon$ for the error term. Thus, the coefficient from the STIRPAT model would be less than 1, which is a key distinction between IPAT and STIRPAT models. The extended STIRPAT model was constructed with Affluence measured by GDP per capita (GDP), energy intensity (INT) used as a proxy for technology, biomass energy (BMS) measured by Biomass consumption per capita (in kilogram), trade openness (TOP) measured by Export of goods and services + import of goods and services (\% of GDP), foreign direct investment (FDI) measured by Foreign direct investment (net inflows), and population (POP) measured by Population (total), and $\mathrm{CO}_{2}$ is $\mathrm{CO}_{2}$ emissions (kt). As a result, the empirical model for the study as given as;

$$
\mathrm{LnCO}_{2 \text { it }}=\alpha+\beta_{1} \mathrm{LnGDP}_{i t}+\beta_{2} \mathrm{LnBMS}_{\text {it }}+\beta_{3} \mathrm{LnTOP}_{\text {it }}+\beta_{4} \mathrm{LnFDI}_{i t}+\beta_{5} \mathrm{LnPOP}_{\text {it }}+\beta_{6} \mathrm{LnINT}_{i t}+\varepsilon_{\text {it }}
$$


$\beta_{1}-\beta_{6}$ are the unknown parameters to be estimated and $\varepsilon$ represents the standard error term. Thus, the fixed effects from the spatial panel model become;

$$
\begin{aligned}
\operatorname{LnCO}_{2 i, t}=\alpha_{i} & +\rho \sum_{j=1}^{N} W_{i j} \operatorname{LnCO}_{i, t}+\beta_{1} \operatorname{LnGDP}_{i, t}+\beta_{2} \operatorname{LnBMS}_{i, t}+\beta_{3} \operatorname{LnTOP}_{i, t}+\beta_{4} \operatorname{LnFDI}_{i, t}+\beta_{5} \operatorname{LnPOP}_{i, t} \\
& +\beta_{5} \operatorname{LnINT}_{i, t}+\gamma_{1} \sum_{j=1}^{N} W_{i j} \operatorname{LnGDP}_{i, t}+\gamma_{2} \sum_{j=1}^{N} W_{i j} \operatorname{LnBMS}_{i, t}+\gamma_{3} \sum_{j=1}^{N} W_{i j} \operatorname{LnTOP}_{i, t} \\
& +\gamma_{4} \sum_{j=1}^{N} W_{i j} \operatorname{LnFDI}_{i, t}+\gamma_{5} \sum_{j=1}^{N} W_{i j} \operatorname{LnPOP}_{i, t}+\gamma_{5} \sum_{j=1}^{N} W_{i j} \operatorname{LnINT}_{i, t}+\pi_{i t}
\end{aligned}
$$

$$
\pi_{i t}=\vartheta \sum_{j=1}^{N} W_{i j} \tau_{i t}+e_{i t}
$$

Thus, the model in Eq. 5 comprises three spatial impacts characteristics;

$(\alpha)$ endogenous spatial impacts;

$(\beta)$ exogenous spatial impacts;

$$
\sum_{j=1}^{N} W_{i j} \operatorname{LnCO}_{2 i, t}
$$

$$
\sum_{j=1}^{N} W_{i j} \operatorname{LnGDP}_{i, t}, \sum_{j=1}^{N} W_{i j} \operatorname{LnBMS}_{i, t}, \sum_{j=1}^{N} W_{i j} \operatorname{LnTOP}_{i, t}, \sum_{j=1}^{N} W_{i j} \operatorname{LnFDI}_{i, t}, \sum_{j=1}^{N} W_{i j} \operatorname{LnPOP}_{i, t}, \sum_{j=1}^{N} W_{i j} \operatorname{LnINT}_{i, t}
$$

and,

$(\gamma)$ residual spatial impacts;

$$
\vartheta \sum_{j=1}^{N} W_{i j} \tau_{i t}
$$




\subsection{Spatial correlation test}

The Moran I's index was used to determine the global spatial auto correlation along West African countries. The index is a regularly used metric for determining the degree of geographical clustering of the attributes of the employed variables. As stated by Moran (1950), the indicator can be calculated as;

$$
\text { Moran's I }=\frac{\mathrm{n} \sum_{\mathrm{i}=1}^{\mathrm{n}} \sum_{\mathrm{j}=1}^{\mathrm{n}} \mathrm{W}_{\mathrm{ij}}^{\mathrm{A}}\left(\mathrm{x}_{\mathrm{i}}-\overline{\mathrm{x}}\right)\left(\mathrm{x}_{\mathrm{j}}-\overline{\mathrm{x}}\right)}{\left(\sum_{\mathrm{i}=1}^{\mathrm{n}} \sum_{\mathrm{j}=1}^{\mathrm{n}} \mathrm{W}_{\mathrm{ij}}^{\mathrm{A}}\right) \times \sum_{\mathrm{i}}^{\mathrm{n}}\left(\mathrm{x}_{\mathrm{i}}-\overline{\mathrm{x}}\right)^{2}}
$$

Where $n$ represent the number of spatial units indicated by $i$ and $j . x$ is the variable of interest, the average of $x$ is given by $\bar{x}$, the $(n \times n)$ weight matrix indicating the interrelation between a variable and its surrounding is given by $W_{i j}^{A}$. Generally, the Moran I's index is evaluated by the $Z$-score, which is calculated as;

$$
Z=\frac{I-E(I)}{\sqrt{\operatorname{var}(I)}}
$$

Where the expectation of the index is given by $\mathrm{E}(\mathrm{I})$; the variance of the index is given by var(I). In effect, the Moran's I index varies from -1 to +1 indicating negatively or positively spatial auto correlation. Furthermore, the Local indicators of spatial association (LISA) which are also used to assess the degree of association between a country and its surroundings is calculated by the expression;

$$
I_{i}=Z_{i}^{\prime}=\sum_{i}^{n} W_{i j} Z_{j}^{\prime}
$$

Where $Z_{i}$ is the standardized form of the variable $x_{i}$ and spatial weight matrix is given by $W_{i j}$. A negative or positive LISA coefficient, on the other hand, suggests surrounding features with differing or similar attribute values. The LISA coefficients (Spatial distribution) could be visualized in illustrating the clusters of low-low values (L-L), high-high values (H-H), and outliers such as low-high (L-H) and high-low (H-L). 
The queen contiguity was used to define the relationship among a country and its neighbors as a spatial unit that shares a common vertex.

\subsection{Spatial econometric models}

In working with spatial interaction and spillover effects among spatial units, the spatial regression model (SRM) outperforms the ordinary least square (OLS) regression in terms of providing in-depth information on spatial correlations between the variables while explicitly accounting for geographical impacts. The SRM includes three basic models; the spatial Durbin model (SDM), the spatial lag model (SLM), and the spatial error model (SEM). The spatial autoregressive process which incorporates both explanatory and response variables in the SDM model can be constructed as (Elhorst, 2014; Sun et al., 2019)

$$
\left\{\begin{array}{c}
Y_{i t}=\beta X_{i t}+\rho W Y_{i t}+\delta W X_{i t}+\varepsilon_{i t} \\
Y_{i t}=\beta X_{i t}+\rho W Y_{i t}+\delta W X_{i t}+u_{i}+\varepsilon_{i t} \\
Y_{i t}=\beta X_{i t}+\rho W Y_{i t}+\delta W X_{i t}+v_{i}+\varepsilon_{i t} \\
Y_{i t}=\beta X_{i t}+\rho W Y_{i t}+\delta W X_{i t}+u_{i}+v_{i}+\varepsilon_{i t}
\end{array}\right\}
$$

Whereas the spatially auto regressive process $(\mathrm{W})$ is incorporated into the explanatory variables in the spatial lag models (SLM) (Elhorst, 2014; Liu et al., 2018). Thus, the SLM models can be defined as;

$$
\left\{\begin{array}{c}
Y_{i t}=\beta X_{i t}+\rho W Y_{i t}+\varepsilon_{i t} \\
Y_{i t}=\beta X_{i t}+\rho W Y_{i t}+u_{i}+\varepsilon_{i t} \\
Y_{i t}=\beta X_{i t}+\rho W Y_{i t}+v_{i}+\varepsilon_{i t} \\
Y_{i t}=\beta X_{i t}+\rho W Y_{i t}+u_{i}+v_{i}+\varepsilon_{i t}
\end{array}\right\}
$$

Lastly, the spatial auto regression process error term denoted by $\emptyset$, whereas the auto correlation error term's spatial influence is given by $\lambda$ are incorporated into the SEM models as noted by You and Lv (2018), thus, it was constructed as;

$$
\left\{\begin{array}{c}
Y_{i t}=\beta X_{i t}+\lambda W \emptyset+\varepsilon_{i t} \\
Y_{i t}=\beta X_{i t}+\lambda W \emptyset+u_{i}+\varepsilon_{i t} \\
Y_{i t}=\beta X_{i t}+\lambda W \emptyset+v_{i}+\varepsilon_{i t} \\
Y_{i t}=\beta X_{i t}+\lambda W \emptyset+u_{i}+v_{i}+\varepsilon_{i t}
\end{array}\right\}
$$


To select the appropriate model for the study, the Lagrange multiplier (LM) diagnostic tests would be employed. The LM diagnostics provides four (4) statistic tests; that is LM error, robust LM error, LM lag, and robust LM lag. Furthermore, the log-likelihood approach, Schwartz criterion (SC), and the Akaike information criterion (AIC) would be used to compare the models to aid in selecting the best model.

\section{Exploratory data analysis}

\subsection{Data and Descriptive statistics}

The study used a balanced data from 29 Sub-African countries from 1995 to 2017 to reveal the influencing factors of $\mathrm{CO}_{2}$ emissions and the spatial effect of $\mathrm{CO}_{2}$ emissions in the region. All data except for the biomass energy data were extracted from the World Bank database. The biomass energy data was incurred from the global material flow database. The natural logarithm was applied to the variables to explicate the estimates as elasticities. The descriptive statistics for the transformed variables are presented in Table 1. The distribution of $\mathrm{CO}_{2}$ emissions and the range of biomass energy consumption and trade openness in Sub-Saharan Africa countries are rendered in Figure 1, Figure 2, and Figure 3 respectively for the years 1995 and 2017.

\section{TABLE 1}




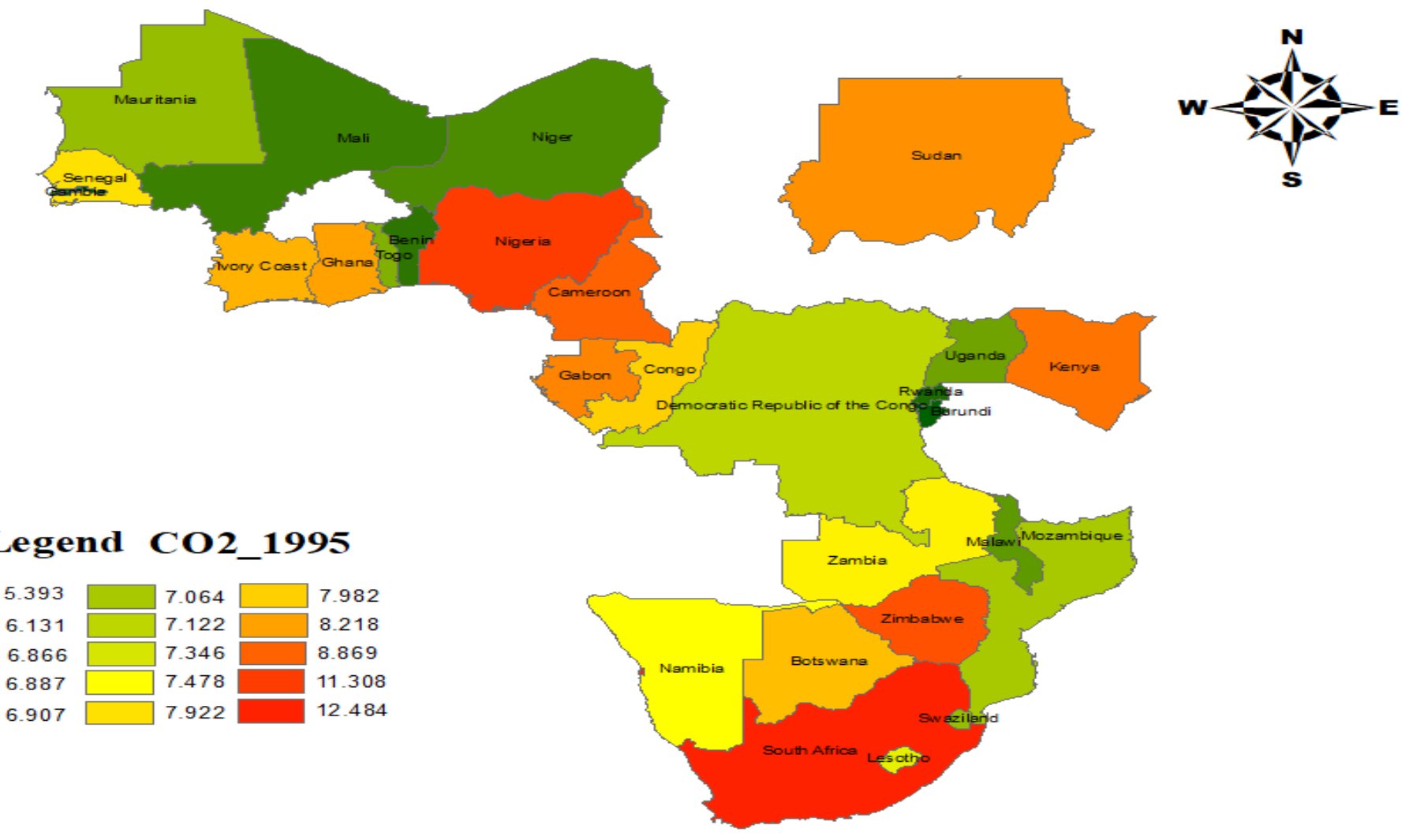

Mauritius

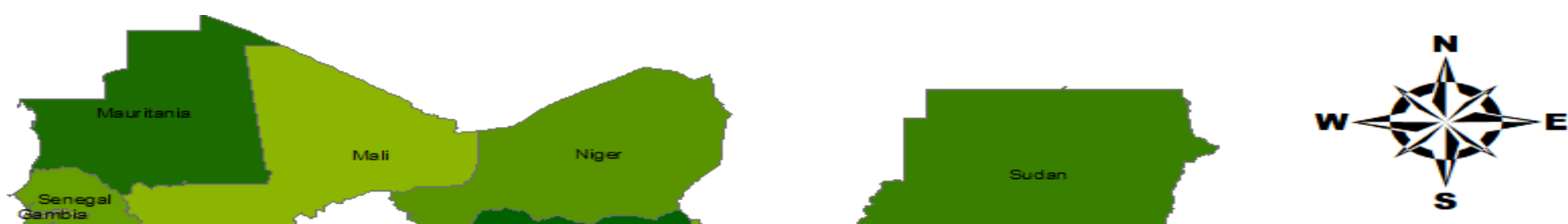

\section{Legend CO2 2017}

\begin{tabular}{|c|c|c|}
\hline 6.291 & 8.373 & 9.247 \\
\hline 6.956 & 8.527 & 9.846 \\
\hline 7.313 & 8.903 & 9.92 \\
\hline 8.077 & 9.026 & 11.634 \\
\hline 8.242 & 9.233 & 12.983 \\
\hline
\end{tabular}

FIGURE 1: $\mathrm{CO}_{2}$ emissions in Sub-Saharan Africa for the years 1995 and 2017 

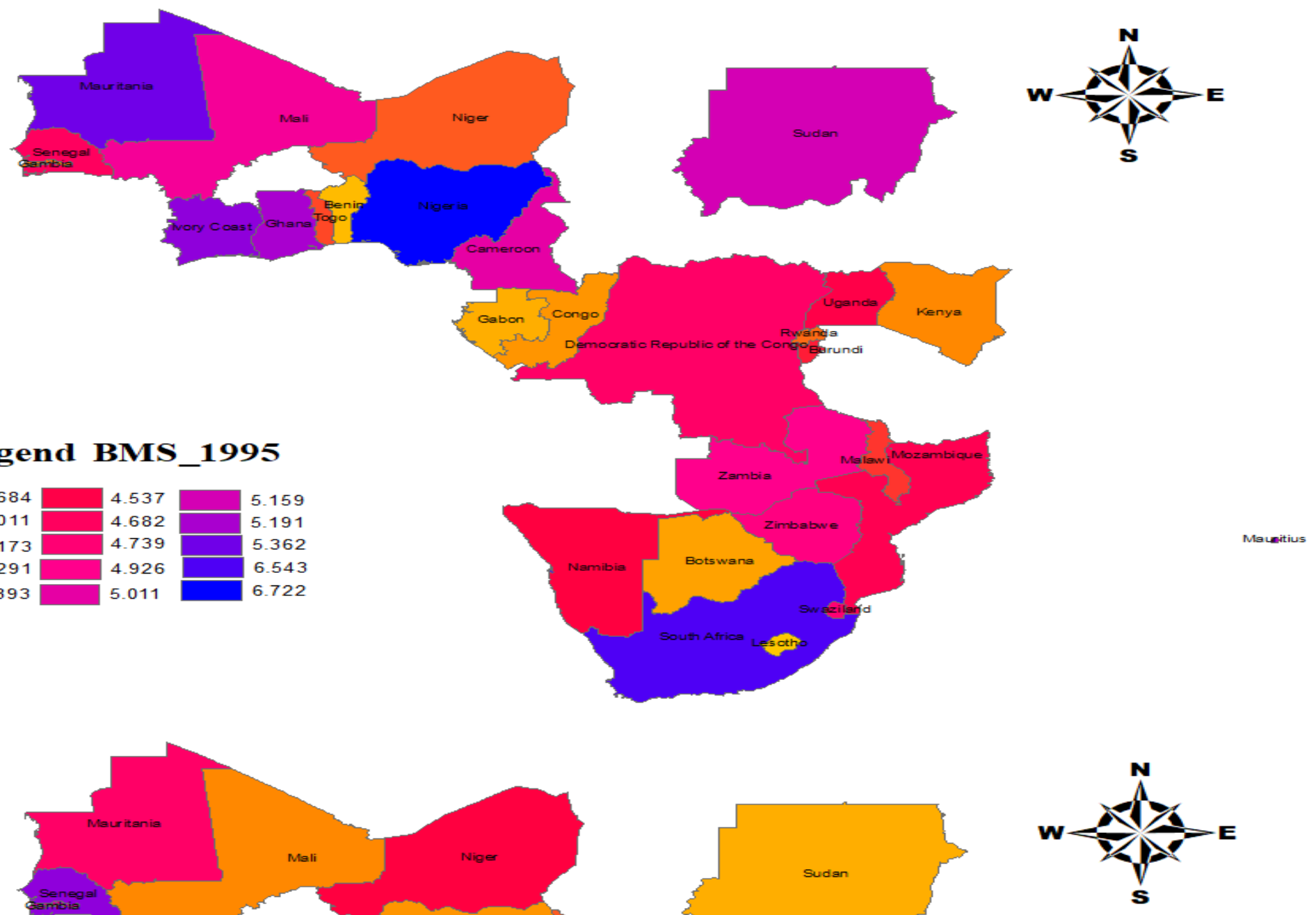

Legend BMS_2017

\begin{tabular}{|l|l|l|l|}
\hline 6.157 & & 7.116 & 7.405 \\
\hline 6.737 & 7.181 & \\
\hline & 7.529 \\
6.907 & 7.274 & 7.969 \\
\hline 6.944 & 7.28 & 8.348 \\
\hline 7.035 & & 7.352 & \\
\hline
\end{tabular}

FIGURE 2: Biomass energy consumption in Sub-Saharan Africa for the years 1995 and 2017. 


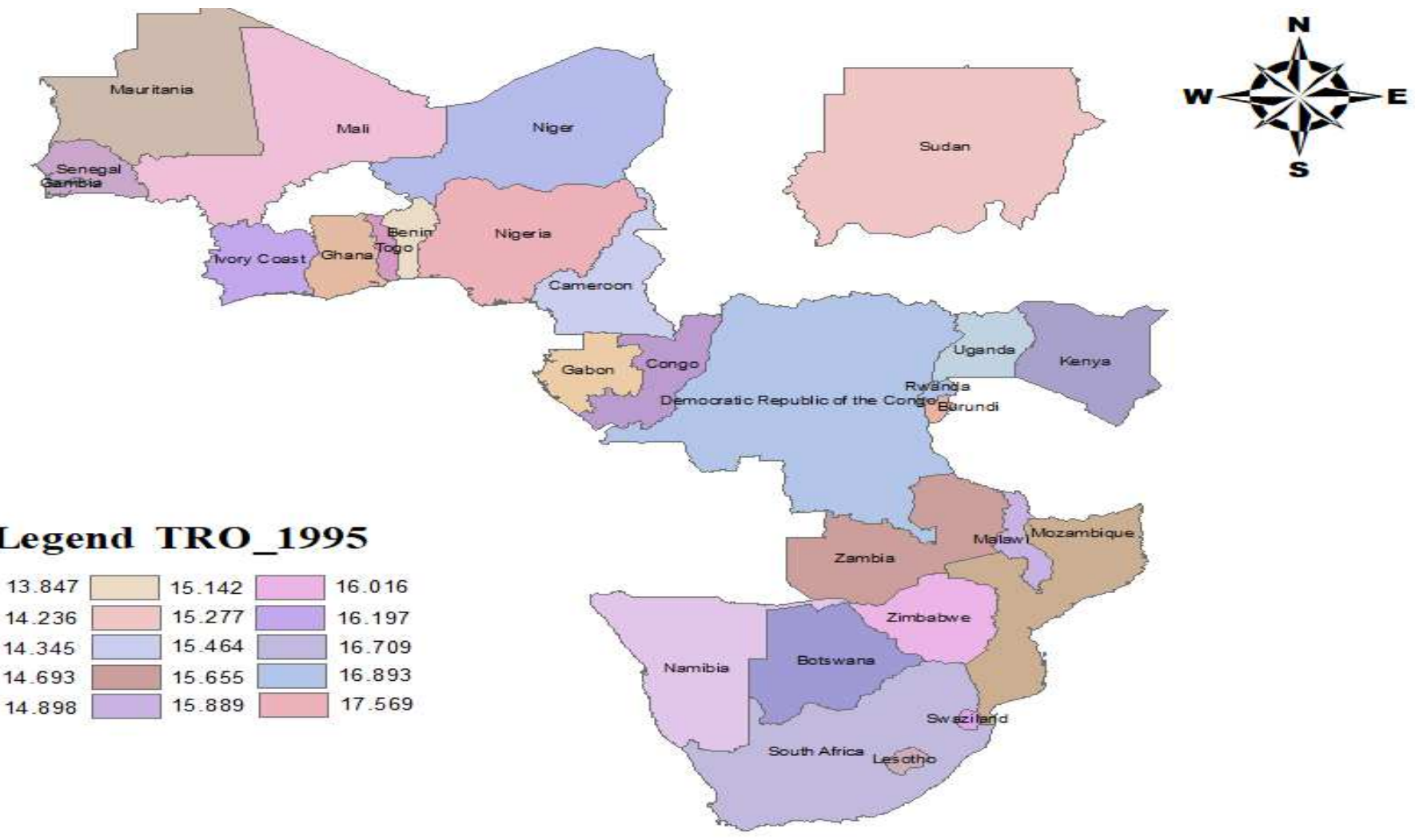

Malecitius

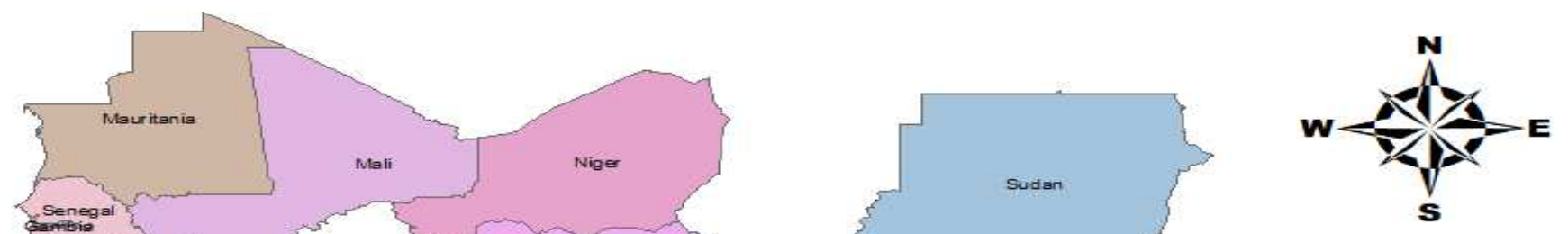

\section{Legend TRO_2017}

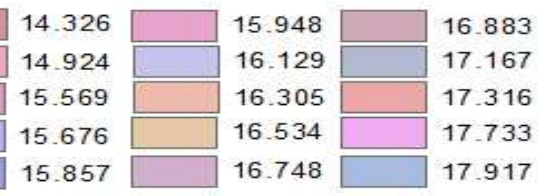




\subsection{Correlation test and Cross-section dependence test}

With regards to the relationship among the exogenous variables, it could be inferred from Figure 4 that there is no substantial association between the independent variables since the coefficient of correlation among the variables are less than 0.7 . In conclusion, each of the explanatory variable influence the dependent variable in a unique way. Econometrically, it was vital to check the stationarity of the employed variables. Thus, the second generations panel unit root tests (CIPS and CADF), indicated that the variables were I (0) at level, but they turned to I (1) after the first difference as presented in Table 2.

\section{TABLE 2}

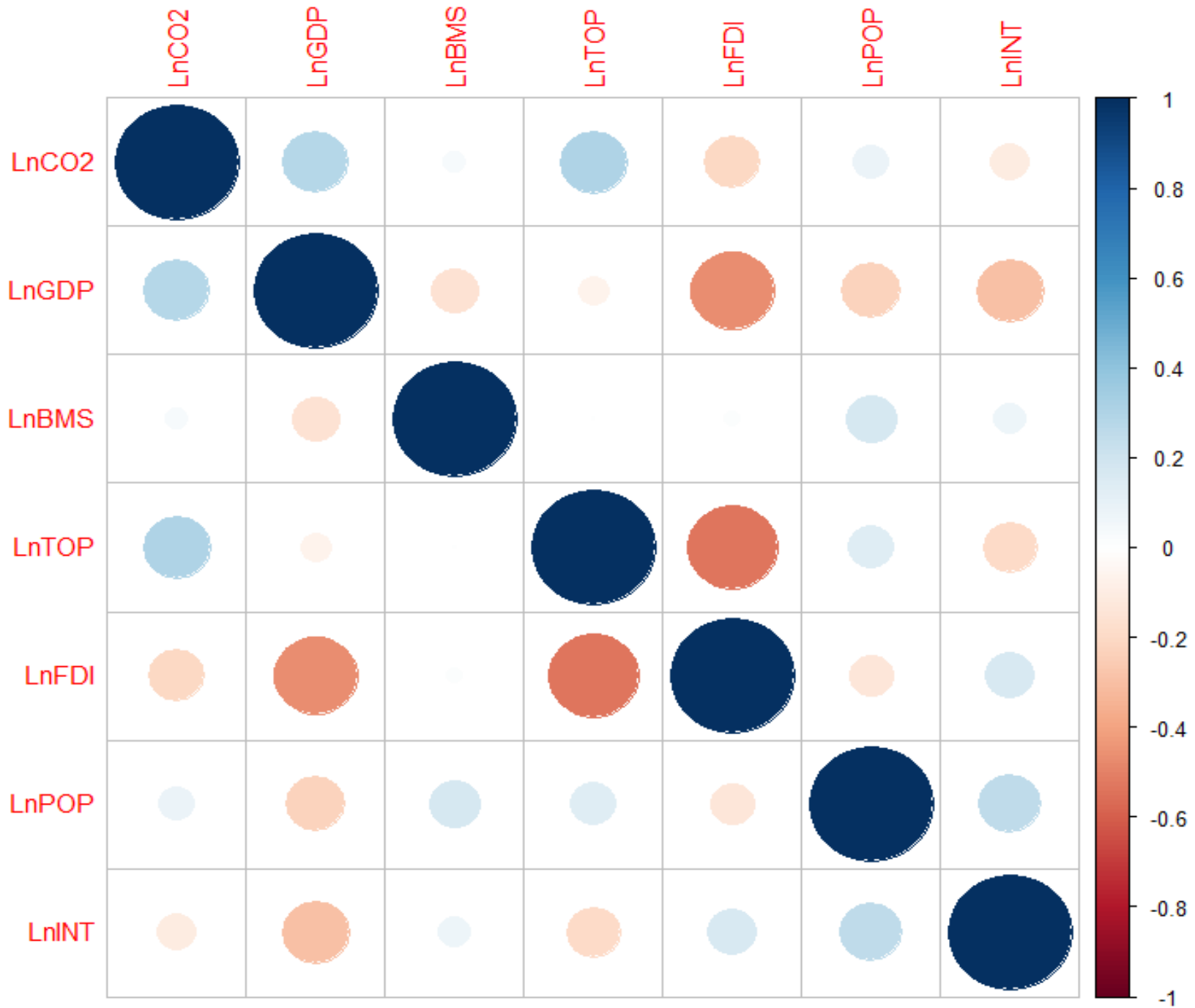

FIGURE 4: Corroplot of the employed variables 


\section{Empirical Results and Discussion}

\subsection{The Spatial auto correlation averment}

Before unveiling the spillover effect of the dependent variable and effect exogenous variables, it was vital to appraise whether there is a possibility of spatial auto correlation of $\mathrm{LnCO}_{2}$ among a country and its neighboring states. This was done by using the Local Indicators of Spatial Association (LISA) analytical tool and the Moran's I assessment. It was observed from the LISA map (Figure 5) that Nigeria and South Africa observed a High-High pattern $(\mathrm{H}-\mathrm{H})$ local spatial agglomeration impact. For the selected years (1995, 2002, 2010, and 2017), countries like Ghana, cote d'Ivoire, Cameroun, Gabon, Congo Rep, Sudan, Kenya, Senegal, Botswana, and Zimbabwe were seen to have a High-Low pattern (H-L). For Low-High (L-H) local spatial agglomeration impacts countries Mauritania, DR Congo, Zambia, Namibia, Uganda, Malawi, Mozambique, Eswatini, and Togo. Benin, Rwanda, Burundi, and Niger were seen to have a LowLow (L-L) local spatial agglomeration impact. Table 3 indicated that the Moran'I values were also statistically significant. Consequently, Moran's plots for the years 1995, 2002, 2010, and 2017 were also assessed as shown in Figure 6 to further explore the spatial auto correlation.

\section{TABLE 3}



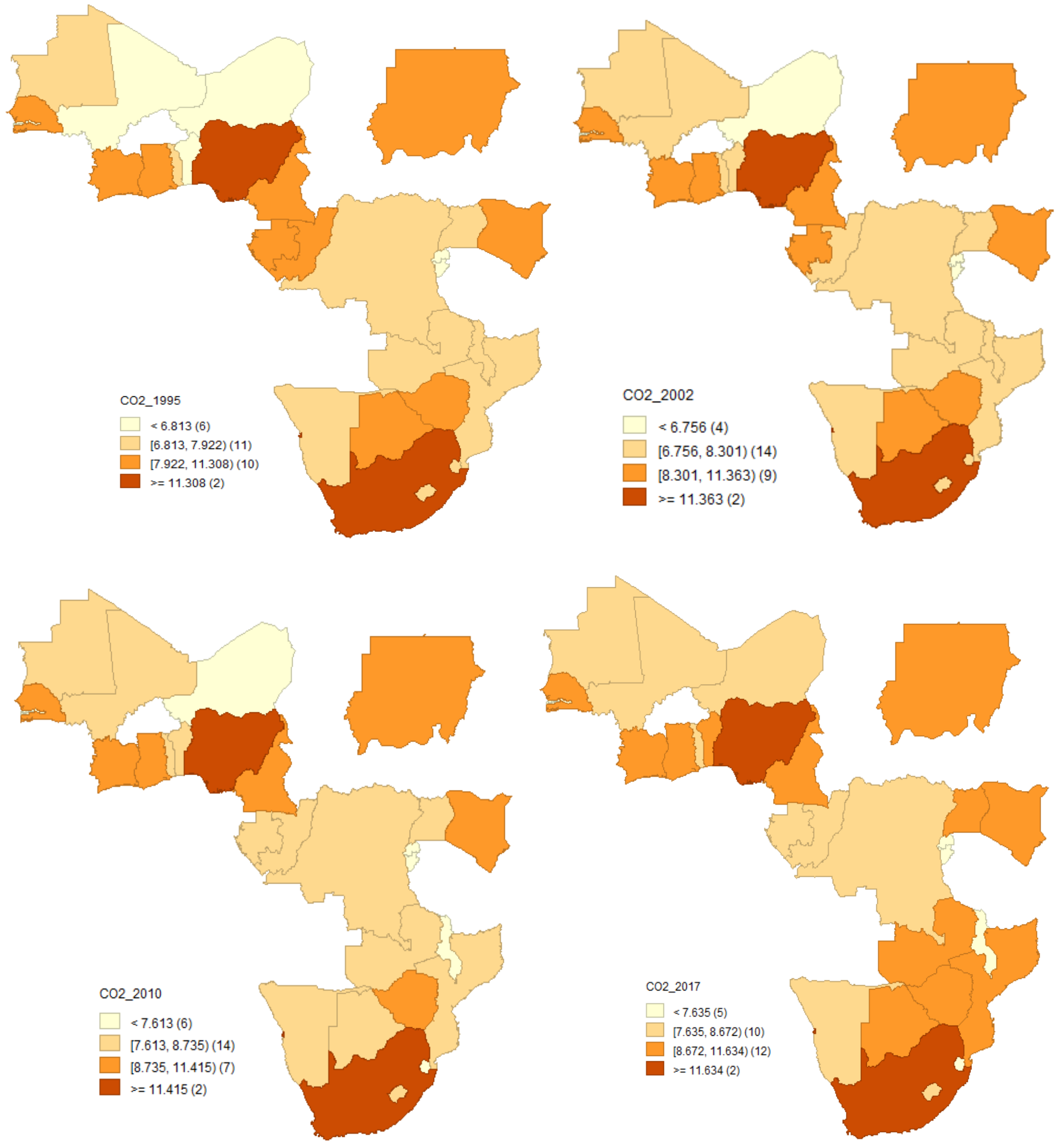

FIGURE 5: LISA maps for the Sub-Saharan Africa in 1995, 2002, 2010, and 2017 

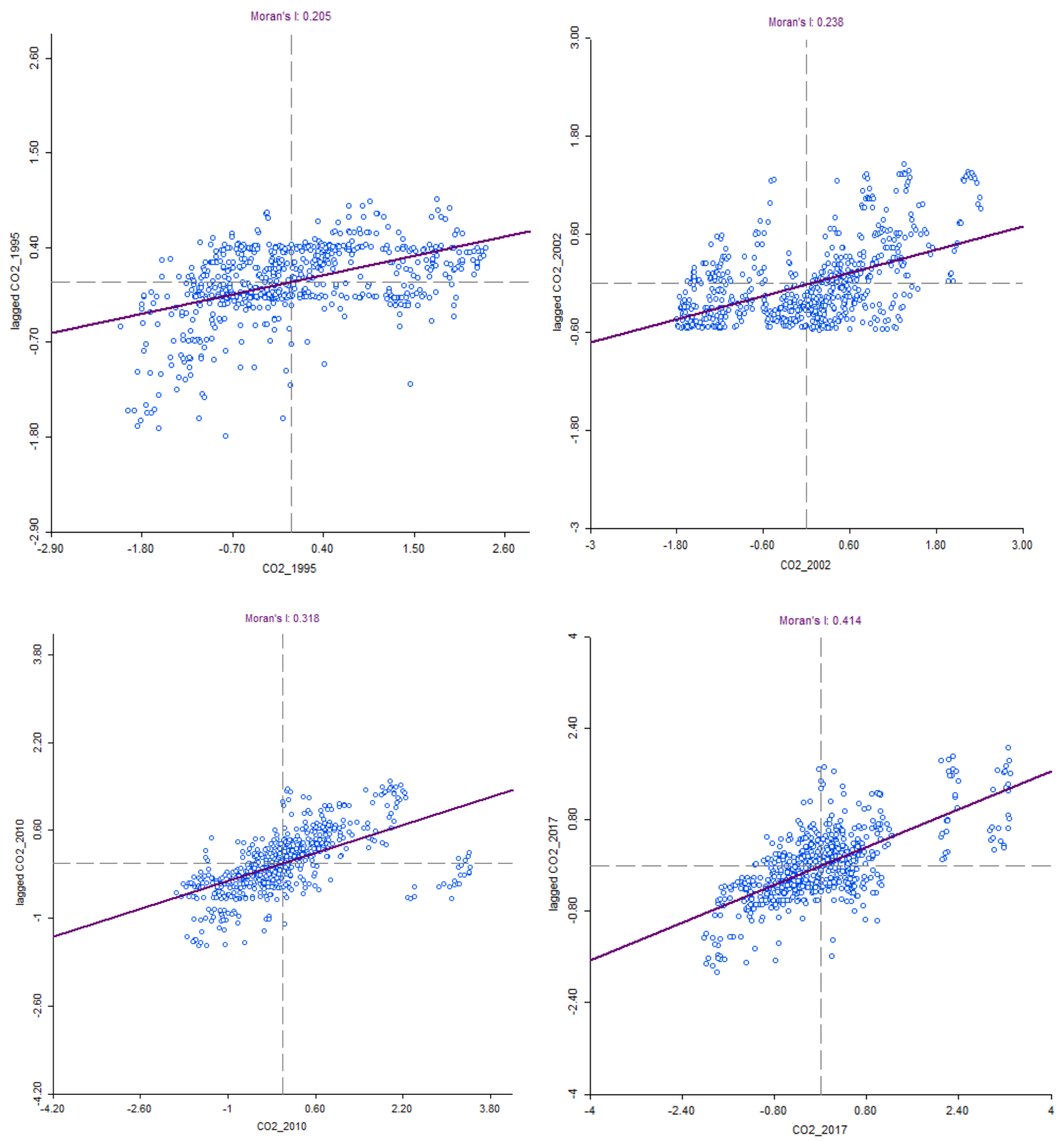

FIGURE 6: Moran' I plot for Sub-Saharan Africa in 1995, 2002, 2010, and 2017 


\subsection{Non-Spatial panel model}

The study used a non-spatial panel model to investigate whether there was any spatial dependency across spatial units by employing the traditional Lagrange multiplier test. From this test, the non-spatial analysis was rejected. The rejection of the non-spatial models indicates that the spatial model must be used to capture the spatiality via the techniques described in section 2.4. Table 5 displays the non-spatial outcomes. The LM and its robust tests were used to investigate the geographic dependency variable. The results show that the spatial model is supported by all four categories of fixed effects at a $1 \%$ significance level. As a result, the findings disprove the premise that there is no geographical reliance, demonstrating the presence of spatial correlation.

\section{TABLE 4}

\subsection{Spatial Durbin model}

The selection of the best model (SAR, SDM, or SEM) for the study was done by relying on the LR test and Wald test. The Wald test $(66.32, \mathrm{P}=0.000)$ indicates that the SDM model is better suited to the SAR model at a $1 \%$ significance. Similarly, the LR test $(47.54, P=0.000)$, rejects the appropriateness of the SEM model, leading to the conclusion that the SDM model is more convenient. The Hausman test was also performed to ascertain the best model between the random effects and the fixed effects. Table 6, indicates that at a $1 \%$ significance level, with the Hausman test $(133.73, P=0.000)$, the fixed-effect model is more appropriate in explaining the estimates. From Table 6, it could be seen that with a

0.8113 goodness-of-fit and a log-likelihood value (177.411), the spatial fixed effect model (first column) surmount the other models. As a result, the interpretations will be restricted to their coefficients. The estimate of the spatial lagged component of the dependent variable was substantial and positive, showing that $\mathrm{CO}_{2}$ emissions from neighboring states had a positive impact on a country's $\mathrm{CO}_{2}$ emissions. The spatial auto correlation LR test in Table 4 and Moran I's plots support this conclusion. The estimates revealed that a percentage rise in an average $\mathrm{CO}_{2}$ emissions of the surrounding countries cause an increase of $0.137 \%$ in the focal country's environment. The estimates for the explanatory variables from the SDM model can't be 
stated as the marginal effects because of the geographical auto correlation, and thus can't adequately reflect the spatial spillover impact of the employed variables. The study thus, went on to estimate the indirect, direct, and total effects to quantify the impact of the explanatory variables and their spillover on $\mathrm{CO}_{2}$ emissions.

\section{TABLE 5}

\subsection{The estimates of direct, indirect, and total effects of the SDM model}

The decomposition of the direct and indirect effects from the SDM is shown in Table 6. The SDM's direct and indirect effects are extremely close to the matching of the spatial fixed effects. The existing variance in values, on the other hand, is owing to the existence of feedback effects that emanate from neighboring countries. This is contained in two parts (a) $\left(\rho \sum \mathrm{W} * \mathrm{CO}_{2}\right)$, and (b) $\left(\sum W_{i t} X_{i t \gamma}\right)$.

In reference to Table 6, a 1\% increase in BMS has the possibility of reducing a country's environmental pollution by $0.089 \%$ (direct effect), while a $1 \%$ increase of BMS in neighboring countries turns to reduce $\mathrm{CO}_{2}$ emissions by $0.022 \%$ in a focal country. Thus, in total, a country reduces emissions of $\mathrm{CO}_{2}$ in the whole of Sub-Sahara Africa region by $0.111 \%$ by the usage of BMS. The negative association between $\mathrm{CO}_{2}$ emissions and BMS observed indicates that BMS improves the quality of air in the atmosphere in Sub-Saharan African countries. This implies that the effectuation of advanced biomass conversion technologies would lessen the emissions of pollutants in the region. As a result, by shifting energy demand away from traditional energy sources, BMS would transform decarbonized economies through pollution reduction. The quality of the environment would be achieved by lowering fossil fuel usage, as well as it associated emissions that come with it. Since the production of BMS is a cost-effective one, it motivates the investment into BMS because increased economic growth creates opportunities. As a result, BMS can help societies tackle climate change and global warming, while simultaneously ensuring a country's energy security. BMS asseverates a low-carbon development paradigm that is linked to effective pollution control measures. These findings disclosed that biomass energy help regulate pollution in the region. This observation collaborates with the study done by Magazzino et al. (2021) in Germany, where 
they revealed that biofuel has a negative effect on $\mathrm{CO}_{2}$ emissions by using machine learning algorithms. In the similar way, the work done by Sulaiman and Abdul-Rahim (2020) affirmed the negative effect of biomass energy on $\mathrm{CO}_{2}$ emissions in Africa.

The elasticity of TOP exerted on $\mathrm{CO}_{2}$ emissions from both the direct and indirect effects was identified to be positive and statistically significant. More specifically, a $1 \%$ increment in TOP in a focal country has the possibility of increasing $\mathrm{CO}_{2}$ emissions by $0.163 \%$ in its own atmosphere, while a percentage increase of TOP in a neighboring state turns to increase pollution by $0.035 \%$. The possible inference that could be made on the positive impact of TOP on $\mathrm{CO}_{2}$ emissions is that free trade among the African countries has positive environmental outcomes due to the technique, effects of scale, and composition. This free trade has helped expand the trading partners of the economies both close and far geographically. Generally, trade has a positive impact on the environment through economic growth. Due to the scale effect of enhancing energy consumption, economic growth usually has a positive effect on the environment at the betimes stages of development. Since more focus is directed on economic growth instead of pollution control in the early stages of development, the scale effect shows that pollutants emissions are raising as a result of increasing energy usage and economic activity. Thus, for the total effect, a unit increase of TOP in a country pollutes its whole region by $0.198 \%$. These findings indicate that heightening a country's own TOP increases emissions of $\mathrm{CO}_{2}$ in its adjacent countries and its own territory. The provided results propose that TOP has a positive and substantial impact on the emissions of $\mathrm{CO}_{2}$, thus, TOP had an increasing effect on $\mathrm{CO}_{2}$ emissions. The positive impact of TOP obtained on the emissions of $\mathrm{CO}_{2}$ is in line with work done by Ragoubi and Mighri (2021), where they stated that TOP has a positive spatial effect on $\mathrm{CO}_{2}$ emissions in 54 middle-income countries. Likewise, the study done by Mahmood (2020) confirmed the positive spatial impact of TOP on environmental degradation in North America.

The estimates of FDI for both the direct and indirect effects were statistically significant. Specifically, a $1 \%$ increment in FDI in a focal country has the possibility of heightening $\mathrm{CO}_{2}$ emissions in its own environment by $0.201 \%$, whereas a unit increment in FDI in any country in the region turns to step up 
emissions by in the neighboring state by $0.094 \%$. The possible explanation for the positive effect of FDI on $\mathrm{CO}_{2}$ emissions could be attributed to the massive mining and other production operations by foreign corporations. These operations had raised the level of environmental degradation in the Sub-Saharan Africa region. Generally, FDI has the potential to drive economic development in their host country by transferring sophisticated technologies which raise productivity and increase economic growth. FDI introduces new production methods to local enterprises and provides labor skills, management practices, and new products resulting in more job chances for indigenous people. Furthermore, FDI in Sub-Saharan Africa has aided in the creation of a competitive corporate environment, which has fueled the economic expansion in most Sub-Saharan Africa. The study done by Mahmood et al. (2020) in North Africa collaborates with the result obtained in this study, where they stated that FDI has a positive spatial impact on $\mathrm{CO}_{2}$ emissions. Likewise, the study done by Mahmood and Furqan (2021) collaborates these findings, where they stated that FDI has a significant spillover effect in Gulf Cooperation Council countries. However, the study done by Abdo et al. (2020) in Arab countries revealed that even though the direct effect of FDI is significant, its indirect (spillover) effect is statistically insignificant.

Similarly, the results revealed that $\mathrm{CO}_{2}$ emissions are induced by GDP, with both indirect and direct effects being statistically significant and positive. The elasticities of GDP for both the direct and indirect effects were statistically significant and positive at a 5\% and $10 \%$ level of significance respectively. More specifically, a unit gain in GDP corresponds to $0.112 \%$ in a focal country's own environment, while a $0.077 \%$ increase is induced by its neighboring countries. A possible reason for the positive effects of GDP on $\mathrm{CO}_{2}$ emissions could be that the Sub-Saharan African countries are still relying heavily on conventional fossil fuels for their economic development. As a result, $\mathrm{CO}_{2}$ emissions resulting from the combustion of oil and coal have increased significantly in the region. Based on this positive effect of GDP on $\mathrm{CO}_{2}$ emissions, it could be concluded that if the Sub-Saharan African countries aim to decouple $\mathrm{CO}_{2}$ from economic growth, they must modify their energy system to a sustainable and clean structure. This observation collaborates with the results obtained by Khan and Bin (2020) in the Belt and Road Initiative, 
where they stated a positive spillover effect of GDP on $\mathrm{CO}_{2}$ emissions. Likewise, the study done by Espoir and Sunge (2021) in Africa also observed the significance of the indirect and direct impact of GDP on $\mathrm{CO}_{2}$ emissions.

Lastly, considering the marginal effects of other parameters in the model, both the direct and indirect effects of POP were observed to be statistically significant and positive, indicating that increasing POP turns to have a deteriorating effect on the environment. While the elasticity predicted for the direct effect of INT was statistically significant and negative at a $10 \%$ level, unveiling that a $1 \%$ increase of INT in the local country reduces the emissions of $\mathrm{CO}_{2}$ by $0.137 \%$. As result, a country with a higher INT is inclined to have fewer $\mathrm{CO}_{2}$ emissions. The indirect effect of INT was also statistically significant and negative at a $5 \%$ significant level, thus a $0.055 \%$ reduction in $\mathrm{CO}_{2}$ emissions was observed in a local country as a result of a $1 \%$ increase of INT in neighboring countries.

\section{TABLE 6}

\section{Conclusion and Policies implication}

Employing a data set of 29 out of 46 Sub-Saharan countries from 1995 to 2017, the spatial econometric approaches and the extended STIRPAT model were used to inquire the effect of biomass energy and trade openness on environmental pollution. Thus, some important outcomes and conclusions based on the aforementioned results and discussions were as follows; The Moran's index and the LISA maps for the selected years indicate the existence of spatial auto correlation. The findings suggest that increasing the usage in biomass energy consumption in a focal country turns to reduces the country's own $\mathrm{CO}_{2}$ emissions and also reduces the emissions of its adjacent countries. Likewise, increasing trade openness in a local country correspondently increases $\mathrm{CO}_{2}$ emissions in its own territory and as well increasing the pollution in the adjacent countries. Consequently, based on the illation obtained during the study, some policy implications derived in order to bring the Sub-Saharan African region onto a neutral $\mathrm{CO}_{2}$ emissions paths are as follows;

1) Governments in Sub-Saharan African should enhance their investments in biomass energy initiatives, which could include extensive research and development. Based on the findings of this 
study, this could aid in the fight against environmental issues specifically $\mathrm{CO} 2$ related pollution. This may be able to attract foreign investors through FDI in order to boost biomass energy production. Thus, to meet the region's environmental sustainability targets, $\mathrm{CO}_{2}$ emissions could be reduced by using biomass instead of fossil fuels.

2) In order to completely accomplish the goal of the Sub-Saharan African countries in reducing $\mathrm{CO}_{2}$ emissions and achieving a neutral-carbon region, it is important to optimize, increasing energy intensity. Meanwhile, it is critical to boosting the use of clean energy through changing industrial and international trade policies in order to promote the role of the structure of energy consumption.

3) Sub-Saharan African could develop appropriate policies to optimize energy consumption and endeavor to break free from the chains of traditional energy consumption as quickly as feasible by all its countries. When it comes to the impact of energy consumption on the emissions of $\mathrm{CO}_{2}$, traditional energy consumption (coal and oil) is heavy in some SSA countries. Thus, Sub-Saharan African countries should continue to enhance the share of the new energy sources in the energy consumption structure, such as natural gas, solar, and wind energy. As a result, Sub-Saharan African countries should pay close attention to the growth of the renewable energy industry, implement appropriate preference policies, encourage the development of the renewable energy industry, and enhance the proportion of renewable energy consumption.

4) By means of cleaning up the Sub-Saharan African environment, these countries should support ecologically friendly FDI inflow. Because biomass energy consumption improves the quality of the environment in these states, shifting energy consumption from energy mix to renewable energy (Biomass) is the best option. Thus, the attraction of more environmentally friendly FDI and investing in the development of human capital is a necessity for the region because it would boost the total productivity factor and energy efficiency as well.

5) Sub-Saharan African must continually open up its trading policies and shift its competitive advantage in favor of cleaner production, as well as boost inter-country technology collaboration, including both emissions and production, in order to maintain the emissions of $\mathrm{CO}_{2}$ at a low level. 
Again, to prevent countries from more pollution in the future, Sub-Saharan African could impose stringent regulations, such as imposing more technological procedures, which will allow emissions to be suppressed and, ultimately, environmental quality to improve. Optimizing and readjusting industrial structures, on the other hand, are the most vital approaches in reducing the emissions of $\mathrm{CO}_{2}$, as successful transformation of industrial structures would result in a significant reduction in $\mathrm{CO}_{2}$ emissions.

\section{References}


Abban, O. J., Wu, J., \& Mensah, I. A. (2020). Analysis on the nexus amid CO 2 emissions, energy intensity, economic growth, and foreign direct investment in Belt and Road economies: does the level of income matter? Environmental Science and Pollution Research, 27(10), 11387-11402.

Abdo, A.-B., Li, B., Zhang, X., Lu, J., \& Rasheed, A. (2020). Influence of FDI on environmental pollution in selected Arab countries: a spatial econometric analysis perspective. Environmental Science \& Pollution Research, 27(22).

Abdulyekeen, K. A., Umar, A. A., Patah, M. F. A., \& Daud, W. M. A. W. (2021). Torrefaction of biomass: Production of enhanced solid biofuel from municipal solid waste and other types of biomass. Renewable and Sustainable Energy Reviews, 150, 111436.

Ajmi, A. N., \& Inglesi-Lotz, R. (2020). Biomass energy consumption and economic growth nexus in OECD countries: A panel analysis. Renewable Energy, 162, 1649-1654.

Alola, A. A., Ozturk, I., \& Bekun, F. V. (2021). Is clean energy prosperity and technological innovation rapidly mitigating sustainable energy-development deficit in selected sub-Saharan Africa? A myth or reality. Energy Policy, 158, 112520.

Ansari, M. A., Haider, S., \& Khan, N. (2020). Does trade openness affects global carbon dioxide emissions: evidence from the top $\mathrm{CO} 2$ emitters. Management of Environmental Quality: An International Journal.

Bakke, G. (2021). Pivoting toward Energy Transition 2.0: learning from electricity. In Research Handbook on Energy and Society. Edward Elgar Publishing.

Carley, S., \& Konisky, D. M. (2020). The justice and equity implications of the clean energy transition. Nature Energy, 5(8), 569-577.

Dietz, T., \& Rosa, E. A. (1994). Rethinking the environmental impacts of population, affluence and technology. Human ecology review, 1(2), 277-300.

Dudley, B. (2018). BP statistical review of world energy. BP Statistical Review, London, UK, accessed Aug, 6(2018), 00116.

Ehrlich, P. R., \& Holdren, J. P. (1971). Impact of population growth. Science, 171(3977), 1212-1217.

Ehrlich, P. R., \& Holdren, J. P. (1972). Critique. Bulletin of the Atomic Scientists, 28(5), 16-27.

Elhorst, J. P. (2014). Matlab software for spatial panels. International Regional Science Review, 37(3), 389405.

Espoir, D. K., \& Sunge, R. (2021). Co2 Emissions and Economic Development in Africa: Evidence from A Dynamic Spatial Panel Model.

Gao, J., \& Zhang, L. (2021). Does biomass energy consumption mitigate CO2 emissions? The role of economic growth and urbanization: evidence from developing Asia. Journal of the Asia Pacific Economy, 26(1), 96-115.

Gyamfi, B. A., Ozturk, I., Bein, M. A., \& Bekun, F. V. (2021). An investigation into the anthropogenic effect of biomass energy utilization and economic sustainability on environmental degradation in E7 economies. Biofuels, Bioproducts and Biorefining, 15(3), 840-851.

Karnauskas, K. B., Miller, S. L., \& Schapiro, A. C. (2020). Fossil fuel combustion is driving indoor $\mathrm{CO} 2$ toward levels harmful to human cognition. GeoHealth, 4(5), e2019GH000237.

Khan, R. (2021). Beta decoupling relationship between CO2 emissions by GDP, energy consumption, electricity production, value-added industries, and population in China. Plos one, 16(4), e0249444.

Khan, Y., \& Bin, Q. (2020). The environmental Kuznets curve for carbon dioxide emissions and trade on belt and road initiative countries: A spatial panel data approach. The Singapore Economic Review, 65(04), 1099-1126.

Liu, Q., Wang, S., Zhang, W., Zhan, D., \& Li, J. (2018). Does foreign direct investment affect environmental pollution in China's cities? A spatial econometric perspective. Science of the total environment, 613, 521-529. 
Magazzino, C., Mele, M., Schneider, N., \& Shahbaz, M. (2021). Can biomass energy curtail environmental pollution? A quantum model approach to Germany. Journal of Environmental Management, 287, 112293.

Mahmood, H. (2020). CO2 Emissions, Financial Development, Trade, and Income in North America: A Spatial Panel Data Approach. SAGE Open, 10(4), 2158244020968085.

Mahmood, H., Alkhateeb, T. T. Y., \& Furqan, M. (2020). Exports, imports, foreign direct investment and CO2 emissions in North Africa: Spatial analysis. Energy Reports, 6, 2403-2409.

Mahmood, H., \& Furqan, M. (2021). Oil rents and greenhouse gas emissions: spatial analysis of Gulf Cooperation Council countries. Environment, Development and Sustainability, 23(4), 6215-6233.

Mahmood, H., Maalel, N., \& Zarrad, O. (2019). Trade openness and CO2 emissions: Evidence from Tunisia. Sustainability, 11(12), 3295.

Millward-Hopkins, J., Steinberger, J. K., Rao, N. D., \& Oswald, Y. (2020). Providing decent living with minimum energy: A global scenario. Global Environmental Change, 65, 102168.

Moran, P. A. (1950). Notes on continuous stochastic phenomena. Biometrika, 37(1/2), 17-23.

Mutascu, M. (2018). A time-frequency analysis of trade openness and CO2 emissions in France. Energy Policy, 115, 443-455.

Nyika, J., Adediran, A. A., Olayanju, A., Adesina, O. S., \& Edoziuno, F. O. (2020). The potential of biomass in Africa and the debate on its carbon neutrality. In Biomass. IntechOpen.

Ragoubi, H., \& Mighri, Z. (2021). Spillover effects of trade openness on CO2 emissions in middle-income countries: A spatial panel data approach. Regional Science Policy \& Practice, 13(3), 835-877.

Rahman, M. M., Saidi, K., \& Mbarek, M. B. (2020). Economic growth in South Asia: the role of CO2 emissions, population density and trade openness. Heliyon, 6(5), e03903.

Schulze, P. C. (2002). I= PBAT. Ecological Economics, 40(2), 149-150.

Sulaiman, C., \& Abdul-Rahim, A. S. (2020). Can clean biomass energy use lower CO 2 emissions in African economies? Empirical evidence from dynamic long-run panel framework. Environmental Science and Pollution Research, 27(30), 37699-37708.

Sun, J., Wang, J., Wang, T., \& Zhang, T. (2019). Urbanization, economic growth, and environmental pollution: partial differential analysis based on the spatial Durbin model. Management of Environmental Quality: An International Journal.

Ulucak, R. (2020). Linking biomass energy and CO2 emissions in China using dynamic autoregressivedistributed lag simulations. Journal of Cleaner Production, 250, 119533.

Waggoner, P. E., \& Ausubel, J. H. (2002). A framework for sustainability science: A renovated IPAT identity. Proceedings of the National Academy of Sciences, 99(12), 7860-7865.

Wang, Z., Bui, Q., \& Zhang, B. (2020). The relationship between biomass energy consumption and human development: Empirical evidence from BRICS countries. Energy, 194, 116906.

You, W., \& Lv, Z. (2018). Spillover effects of economic globalization on CO2 emissions: a spatial panel approach. Energy Economics, 73, 248-257.

Zafar, M. W., Sinha, A., Ahmed, Z., Qin, Q., \& Zaidi, S. A. H. (2021). Effects of biomass energy consumption on environmental quality: the role of education and technology in Asia-Pacific Economic Cooperation countries. Renewable and Sustainable Energy Reviews, 142, 110868.

Zhang, J., Zhang, K., \& Zhao, F. (2020). Spatial effects of economic growth, energy consumption and environmental pollution in the provinces of China-An empirical study of a spatial econometrics model. Sustainable Development, 28(4), 868-879.

Table 1: Descriptive statistics

$\begin{array}{lllllll}\mathrm{LnCO}_{2} & \text { LnGDP } & \text { LnBMS } & \text { LnTOP } & \text { LnFDI } & \text { LnPOP } & \text { LnINT } \\ \end{array}$




\begin{tabular}{|c|c|c|c|c|c|c|c|}
\hline Mean & 8.058 & 6.806 & 7.321 & 15.552 & 18.803 & 16.012 & 21.593 \\
\hline Std.Dev & 1.506 & 0.051 & 1.132 & 1.078 & 2.126 & 1.259 & 1.796 \\
\hline Min & 5.010 & 4.630 & 4.755 & 13.270 & 9.344 & 13.739 & 18.096 \\
\hline Max & 13.012 & 9.288 & 9.334 & 18.278 & 23.014 & 19.067 & 27.739 \\
\hline Skewness & 1.030 & 0.434 & -3.047 & 0.118 & -1.055 & -0.028 & 1.021 \\
\hline Kurtosis & 4.889 & 2.431 & 1.595 & 2.348 & 5.221 & 2.301 & 4.632 \\
\hline Jarque-Bera & 221.595 & 30.552 & 89.517 & 13.879 & 265.978 & 16.916 & 1469.331 \\
\hline Probability & 0.000 & 0.000 & 0.000 & 0.000 & 0.000 & 0.000 & 0.000 \\
\hline Observations & 680 & 680 & 680 & 680 & 680 & 680 & 680 \\
\hline
\end{tabular}

Table 2: Unit root test of the employed variables

\begin{tabular}{|c|c|c|c|c|c|c|c|c|c|c|c|c|}
\hline \multirow[b]{3}{*}{ Variable } & \multicolumn{5}{|c|}{ CIPS } & \multicolumn{7}{|c|}{ CADF } \\
\hline & \multicolumn{2}{|c|}{ Levels } & \multicolumn{3}{|c|}{ First difference } & & \multicolumn{2}{|c|}{ Levels } & \multicolumn{3}{|c|}{ First difference } & \multirow[b]{2}{*}{ Inf. } \\
\hline & $\begin{array}{l}\text { Const } \\
\text { ant }\end{array}$ & $\begin{array}{l}\text { Constant } \\
\text { \&Trend }\end{array}$ & Inf. & $\begin{array}{l}\text { Const } \\
\text { ant }\end{array}$ & $\begin{array}{l}\text { Constant } \\
\text { \&Trend }\end{array}$ & Inf. & $\begin{array}{l}\text { Const } \\
\text { ant }\end{array}$ & $\begin{array}{l}\text { Constant } \\
\text { \&Trend }\end{array}$ & Inf. & $\begin{array}{l}\text { Const } \\
\text { ant }\end{array}$ & $\begin{array}{l}\text { Constant } \\
\text { \&Trend }\end{array}$ & \\
\hline $\mathrm{LnCO}_{2}$ & -1.033 & -1.277 & I (0) & $-3.611^{\mathrm{a}}$ & $-5.221^{\mathrm{a}}$ & I (1) & -1.155 & -1.234 & I (0) & $-5.133^{\mathrm{a}}$ & $-5.301^{\mathrm{a}}$ & I (1) \\
\hline LnGDP & -1.153 & -1.231 & I (0) & $-3.755^{a}$ & $-4.638^{a}$ & I (1) & -1.137 & -1.203 & I (0) & $-4.997^{\mathrm{a}}$ & $-5.215^{\mathrm{a}}$ & I (1) \\
\hline LnBMS & -1.420 & -1.337 & I (0) & $-3.876^{\mathrm{a}}$ & $-4.977^{\mathrm{a}}$ & I (1) & -1.285 & -1.401 & I (0) & $-4.891^{\mathrm{a}}$ & $-4.994^{\mathrm{a}}$ & I (1) \\
\hline LnTOP & -1.311 & -1.433 & I (0) & $-4.133^{\mathrm{a}}$ & $-5.338^{a}$ & I (1) & -1.129 & -1.371 & I (0) & $-5.017^{\mathrm{a}}$ & $-5.273^{\mathrm{a}}$ & I (1) \\
\hline LnFDI & -1.044 & -1.221 & I (0) & $-5.041^{\mathrm{a}}$ & $-5.171^{\mathrm{a}}$ & I (1) & -1.410 & -1.149 & I (0) & $-4.942^{\mathrm{a}}$ & $-5.319^{\mathrm{a}}$ & I (1) \\
\hline LnPOP & -1.214 & -1.403 & I (0) & $-4.828^{\mathrm{a}}$ & $-4.888^{\mathrm{a}}$ & I (1) & -1.066 & -1.364 & I (0) & $-5.045^{\mathrm{a}}$ & $-5.034^{\mathrm{a}}$ & I (1) \\
\hline LnINT & -1.076 & -1.552 & I (0) & $-4.977^{\mathrm{a}}$ & $-5.013^{\mathrm{a}}$ & I (1) & -1.281 & -1.425 & I (0) & $-5.411^{\mathrm{a}}$ & $-5.223^{a}$ & I (1) \\
\hline
\end{tabular}

Note: ${ }^{\mathbf{a}, \mathbf{b}, \mathbf{c}}$ indicates $1 \%, 5 \%$ and $10 \%$ statistical significance levels, respectively

Table 3: Moran' I statistics for $\mathrm{CO}_{2}$ emissions

\begin{tabular}{cccccccc}
\hline Year & Moran & Z-value & p-value & Year & Moran & Z-value & p-value \\
\hline 1995 & $0.211^{\mathbf{a}}$ & 2.455 & 0.000 & 2007 & $0.272^{\mathbf{a}}$ & 3.213 & 0.000 \\
1996 & $0.208^{\mathbf{a}}$ & 2.511 & 0.000 & 2008 & $0.288^{\mathbf{a}}$ & 3.016 & 0.000 \\
1997 & $0.217^{\mathbf{a}}$ & 3.127 & 0.000 & 2009 & $0.304^{\mathbf{a}}$ & 3.455 & 0.000 \\
1998 & $0.220^{\mathbf{a}}$ & 3.031 & 0.000 & 2010 & $0.313^{\mathbf{a}}$ & 2.889 & 0.000 \\
1999 & $0.209^{\mathbf{a}}$ & 3.110 & 0.000 & 2011 & $0.320^{\mathbf{a}}$ & 2.991 & 0.000 \\
2000 & $0.238^{\mathbf{a}}$ & 2.520 & 0.000 & 2012 & $0.347^{\mathbf{a}}$ & 3.044 & 0.000 \\
2001 & $0.240^{\mathbf{a}}$ & 3.447 & 0.000 & 2013 & $0.352^{\mathbf{b}}$ & 3.015 & 0.000 \\
2002 & $0.243^{\mathbf{a}}$ & 2.632 & 0.000 & 2014 & $0.373^{\mathbf{a}}$ & 2.770 & 0.000 \\
2003 & $0.237^{\mathbf{b}}$ & 3.118 & 0.000 & 2015 & $0.407^{\mathbf{b}}$ & 3.300 & 0.000 \\
2004 & $0.250^{\mathbf{a}}$ & 2.811 & 0.000 & 2016 & $0.414^{\mathbf{c}}$ & 2.761 & 0.000 \\
2005 & $0.252^{\mathbf{c}}$ & 2.718 & 0.000 & 2017 & $0.421^{\mathbf{a}}$ & 3.034 & 0.000 \\
2006 & $0.266^{\mathbf{a}}$ & 2.891 & 0.000 & & & & \\
\hline
\end{tabular}

Note: ${ }^{\text {a, b, }}$ indicates $1 \%, 5 \%$ and $10 \%$ statistical significance levels, respectively.

Table 4: Non-Spatial panel model 


\begin{tabular}{|c|c|c|c|c|}
\hline Deteminants & Pooled OLS & $\begin{array}{c}\text { Spatial-fixed } \\
\text { effects }\end{array}$ & $\begin{array}{c}\text { Time-fixed } \\
\text { effects }\end{array}$ & $\begin{array}{c}\text { Spatial and } \\
\text { time-fixed effects }\end{array}$ \\
\hline Constant & $0.131^{b}$ & - & - & - \\
\hline LnGDP & $0.274^{\mathrm{b}}$ & $0.095^{\mathrm{a}}$ & $0.137^{\mathrm{b}}$ & $0.122^{\mathrm{c}}$ \\
\hline LnBMS & $-0.257^{c}$ & $-0.310 c$ & -0.221 & -0.271 \\
\hline LnTOP & $0.422^{\mathrm{c}}$ & $0.344 \mathrm{c}$ & $0.154 b$ & $0.188^{\mathrm{c}}$ \\
\hline LnFDI & $0.270^{\mathrm{c}}$ & $0.231^{b}$ & $0.233^{c}$ & 0.115 \\
\hline LnPOP & $0.311^{\mathrm{b}}$ & 0.232 & $0.291^{b}$ & $0.204^{\mathrm{a}}$ \\
\hline LnINT & $-0.298^{\mathrm{a}}$ & $-0.177 b$ & $-0.277^{\mathrm{c}}$ & -0.156 \\
\hline$\sigma^{2}$ & 0.017 & 0.073 & 0.024 & 0.039 \\
\hline$R^{2}$ & 8.051 & 6.417 & 6.891 & 7.237 \\
\hline Adjusted $R^{2}$ & 7.754 & 6.277 & 6.118 & 7.032 \\
\hline Log-likelihood & 21.114 & 18.037 & 15.631 & 23.221 \\
\hline LM spatial lag & $47.431(0.000)$ & $29.050(0.000)$ & $31.331(0.000)$ & $40.211(0.000)$ \\
\hline Robust LM spatial lag & $30.141(0.000)$ & $22.722(0.000)$ & $19.789(0.000)$ & $29.177(0.000)$ \\
\hline LM spatial error & $12.022(0.000)$ & $10.277(0.000)$ & $7.439(0.000)$ & $11.713(0.000)$ \\
\hline Robust LM spatial error & $9.553(0.000)$ & $6.339(0.000)$ & $6.221(0.000)$ & $8.551(0.000)$ \\
\hline \multirow{3}{*}{$\begin{array}{l}\text { The joint test of } \\
\text { significance } L M\end{array}$} & Fixed effects & Statistics & P-value & \\
\hline & Spatial fixed & 144.179 & 0.000 & \\
\hline & Time fixed & 111.885 & 0.000 & \\
\hline
\end{tabular}

Note: ${ }^{\mathbf{a}, \mathbf{b}, \mathbf{c}}$ indicates $1 \%, 5 \%$, and $10 \%$ statistical significance levels, respectively.

Table 5: Spatial Durbin model

\begin{tabular}{|c|c|c|c|c|c|}
\hline Deteminants & $\begin{array}{c}\text { Spatial-fixed } \\
\text { effects }\end{array}$ & $\begin{array}{l}\text { Time-period } \\
\text { fixed effects }\end{array}$ & $\begin{array}{c}\text { Spatial and } \\
\text { time-fixed } \\
\text { effects }\end{array}$ & $\begin{array}{c}\text { Time-period } \\
\text { random effects }\end{array}$ & $\begin{array}{c}\text { Spatial and } \\
\text { time- random } \\
\text { effects }\end{array}$ \\
\hline $\mathrm{W}^{*} \mathrm{LnCO}_{2}$ & $0.137^{\mathrm{a}}$ & $0.198^{\mathrm{a}}$ & $0.277^{\mathbf{b}}$ & & $0.104^{\mathrm{a}}$ \\
\hline LnGDP & $0.223^{b}$ & $0.211^{\mathrm{a}}$ & -0.192 & -0.083 & $0.051^{b}$ \\
\hline LnBMS & -0.208 & $-0.287^{\mathrm{a}}$ & $-0.101^{\mathrm{c}}$ & $-0.233^{\mathrm{a}}$ & -0.142 \\
\hline LnTOP & $0.357^{\mathbf{b}}$ & 0.155 & 0.078 & 0.177 & $0.121^{b}$ \\
\hline LnFDI & $0.223^{\mathrm{c}}$ & 0.200 & $0.199^{b}$ & $0.212^{\mathrm{a}}$ & $0.179^{\mathrm{a}}$ \\
\hline LnPOP & $0.240^{\mathrm{c}}$ & $0.193^{c}$ & $0.137^{\mathrm{c}}$ & -0.172 & 0.205 \\
\hline LnINT & $-0.233^{c}$ & -0.221 & $-0.133^{c}$ & $-0.153^{c}$ & -0.173 \\
\hline W*LnGDP & $0.106^{\mathrm{c}}$ & $0.176^{\mathrm{b}}$ & 0.082 & 0.109 & $-0.132^{\mathrm{c}}$ \\
\hline W*LnBMS & $-0.211^{\mathrm{a}}$ & $0.205^{\mathrm{c}}$ & 0.110 & $0.088^{\mathrm{a}}$ & $0.188^{\mathrm{a}}$ \\
\hline W*LnTOP & $0.233^{b}$ & 0.100 & $0.214^{\mathrm{a}}$ & $0.222^{\mathrm{a}}$ & $-0.115^{\mathrm{a}}$ \\
\hline W*LnFDI & $0.261^{\mathrm{b}}$ & $0.213^{c}$ & 0.427 & $0.117^{\mathrm{c}}$ & $0.077^{\mathrm{c}}$ \\
\hline W*LnPOP & $0.109^{b}$ & $0.079^{c}$ & 0.108 & $0.277^{\mathfrak{c}}$ & $0.201^{\mathrm{c}}$ \\
\hline W*LnINT & $-0.144^{\mathrm{a}}$ & -0.201 & $-0.208^{c}$ & $-0.139^{a}$ & $-0.166^{\mathrm{a}}$ \\
\hline$\sigma^{2}$ & $0.0041^{\mathrm{a}}$ & $0.0078^{\mathrm{a}}$ & $0.0052^{\mathrm{a}}$ & $0.0017^{\mathrm{a}}$ & $0.0027^{\mathrm{a}}$ \\
\hline$R^{2}$ & 0.8113 & 0.5589 & 0.4761 & 0.4077 & 0.6121 \\
\hline Log-likelihood & 177.411 & 78.703 & 112.881 & 66.031 & 74.871 \\
\hline & \multicolumn{2}{|c|}{ Diagnotic tests } & Statitiscs & P-value & \\
\hline & \multicolumn{2}{|c|}{ Hausman test } & 133.73 & 0.000 & \\
\hline & \multicolumn{2}{|c|}{ Wald test spatial lag } & 66.32 & 0.000 & \\
\hline & \multicolumn{2}{|c|}{ LR test spatial error } & 27.54 & 0.000 & \\
\hline
\end{tabular}


Note: ${ }^{\text {a, b, }}$ indicates $1 \%, 5 \%$ and $10 \%$ statistical significance levels, respectively.

Table 6: Decomposition estimates of direct, indirect, and total effects of SDM model

\begin{tabular}{cccc}
\hline Variables & Direct effects & Indirect effects & Total effects \\
\hline LnGDP & $0.112^{\mathbf{a}}$ & $0.077^{\mathbf{a}}$ & $0.189^{\mathbf{b}}$ \\
LnBMS & $-0.089^{\mathbf{a}}$ & $-0.022^{\mathbf{b}}$ & $-0.111^{\mathrm{a}}$ \\
LnTOP & $0.163^{\mathrm{a}}$ & $0.035^{\mathrm{c}}$ & $0.198^{\mathbf{a}}$ \\
LnFDI & $0.201^{\mathbf{c}}$ & $0.094^{\mathrm{b}}$ & $0.295^{\mathrm{a}}$ \\
LnPOP & $0.122^{\mathbf{b}}$ & $0.042^{\mathrm{a}}$ & $0.164^{\mathbf{a}}$ \\
LnINT & $-0.137^{\mathrm{c}}$ & $-0.055^{\mathrm{b}}$ & $-0.192^{\mathbf{a}}$ \\
\hline
\end{tabular}

Note: ${ }^{\mathbf{a}, \mathbf{b}, \mathbf{c}}$ indicates $1 \%, 5 \%$ and $10 \%$ statistical significance levels, respectively.

\section{Statement on Conflict of Interest:}

On behalf of all authors, the corresponding author states that there is no conflict of interest.

\section{Data Availability / Availability of Data and Materials}

All data generated or analyzed during this study are included in this published article [and its supplementary information files]. 


\section{Supplementary Files}

This is a list of supplementary files associated with this preprint. Click to download.

- Data.xlsx 